\title{
Produtividade de grãos, óleo e massa seca de girassol sob diferentes lâminas de irrigação suplementar
}

\author{
Eder P. G omes ${ }^{1}$, Gregory Fedri ${ }^{2}$, Marizangela R. Ávila ${ }^{3}$, \\ Guilherme A. Biscaro ${ }^{1}$, Rodrigo K. S. Rezende ${ }^{1} \&$ Rodrigo A. Jordan ${ }^{1}$
}

\section{RESU MO}

Este trabalho foi realizado na Universidade Estadual de Maringá, Campus Regional de Umuarama, PR, no ano agrícola de 2008/2009, com o objetivo de avaliar o desenvolvimento da cultura e a eficiência de uso da irrigação em produtividades de grãos, óleo e massa seca da cultura do girassol. Nos tratamentos irrigados ( $L 1, L 2$, L3 e L4) foram adotados coeficientes de cultura (kc) iguais (L2), abaixo (L1) e acima dos propostos pela FAO (L3 e L4). A irrigação favoreceu o desenvolvimento da cultura e as maiores produtividades foram obtidas a partir de valores de kc $100 \%$ acima dos propostos pela FAO (L4). As maiores eficiências de uso de irrigação foram obtidas a partir de valores de kc propostos pela FAO (L2). A produtividade de grãos respondeu, de forma linear, à irrigação com $4.788 \mathrm{~kg} \mathrm{ha}^{-1} \mathrm{em} \mathrm{LO}$ (sem irrigação) e $6.963 \mathrm{~kg} \mathrm{ha}^{-1} \mathrm{em} \mathrm{L4}$. A irrigação não aumentou o teor de óleo, sendo a produtividade de óleo proporcional à produtividade de grãos.

Palavras-chave: safra normal, coeficientes de cultura, lâminas de irrigação, Helianthus annuus L.

\section{Grain yield, oil and dry matter of sunflower under different depths of supplementary irrigation}

\begin{abstract}
This research was conducted at the State U niversity of M aringa, U muarama Campus, Parana State, in the season 2008/2009, with the objective to evaluate the growth and irrigation use efficiency on yield of grain, oil and dry weight of sunflow er under irrigation levels. In the irrigated treatments $(L 1, L 2, L 3$ and L4) the crop coefficients (kc) used were equal (L2), below (L1) and above ( $\mathrm{L} 3$ and $\mathrm{L} 4$ ) those proposed by FAO. The irrigation favored the crop growth and the highest yield was obtained from values of kc $100 \%$ above those proposed by FAO (L4). The highest irrigation use efficiencies were obtained from values of kc by FAO (L2). The grain yield without irrigation (L0) was equal to $4788 \mathrm{~kg} \mathrm{ha}^{-1}$, while in L2 and L4 treatments, grain yields were equal to 6304 and $6963 \mathrm{~kg} \mathrm{ha}^{-1}$, respectively. The irrigation did not increase the oil content and oil yield was proportional to grain yield.
\end{abstract}

Key words: crop coefficients, irrigation levels, Helianthus annuus L.

\footnotetext{
${ }^{1}$ FCA/U FG D. Rodovia D ourados/tahum, km 12, CP 533, CEP 79804-970, D ourados, MS. E-mail: edergomes@ufgd.edu.br; gbiscaro@ufgd.edu.br; rkelson@ufgd.edu.br; rodrigojordan@ufgd.edu.br

2 M estrando em Agronomia, U EM. Campus Universitário, Av. Colombo, 5790, CEP 87020-900, Maringá, PR. E-mail: agrofedri@yahoo.com.br 3 Pesquisadora da área de propagação vegetal, Unidade Regional de Pesquisa O este/Estação Experimental de Santa Tereza do O este/IAPAR. Rodovia PRT 163 Km 188, Cruzinha, CP 02, CEP 85825-000, Santa Tereza do O este, PR. E-mail: marizangela_rizzatti@ hotmail.com
} 


\section{INTRODUÇÃO}

Entre as várias tecnologias desenvolvidas para a produção de girassol, a escolha adequada de cultivar com alto rendimento de grãos ou óleo constitui o principal componente do sistema de produção da cultura (Porto et al., 2007). No entanto, para silagem a produção de massa seca é o componente mais importante, sendo o girassol uma cultura bastante eficiente neste aspecto (Mello et al., 2004).

Apesar da tolerância ao déficit hídrico quando comparada a outras culturas anuais (Tomich et al., 2003), o girassol é sensível à disponibilidade de água no solo (Santos et al., 2002), aumentando a produtividade de grãos, óleo ou massa seca em cultivos sob irrigação.

A cultura do girassol apresenta produtividade média nacional de $1.500 \mathrm{~kg} \mathrm{ha}^{-1}$ (AGRIANUAL, 2008) porém, se adequadamente manejada, a produtividade pode elevar-se para 1.800 a $2.200 \mathrm{~kg} \mathrm{ha}^{-1}$ (Heckler, 2002; Porto et al., 2007; Backes et al.,_2008). Sob irrigação, a produtividade de grãos está geralmente compreendida entre valores de 2.200 a $3.000 \mathrm{~kg} \mathrm{ha}^{-1}$ (Fragella et al., 2002; Smiderle et al., 2005; Silva et al., 2007; Biscaro et al., 2008); apesar disto, a produtividade de grãos de girassol sob irrigação pode superar a $4.000 \mathrm{~kg} \mathrm{ha}^{-1}$ (Goksoy et al. 2004; Karam et al., 2007; Anastasi et al., 2010).

A produtividade de óleo em cultivos de girassol sem irrigação está compreendida numa faixa de $400 \mathrm{a} 1.000 \mathrm{~kg} \mathrm{ha}^{-1}$ mas, quando sob irrigação, pode-se obter produtividade de 700 a $2200 \mathrm{~kg} \mathrm{ha}^{-1}$ (Fragella et al., 2002; Goksoy et al. 2004; Silva et al., 2007; Anastasi et al., 2010).

Alguns resultados apontam para valores de produtividade de massa seca entre 3.000 e $11.000 \mathrm{~kg} \mathrm{ha}^{-1} \mathrm{em}$ cultivos de girassol sem irrigação (Tomich et al., 2003; Mello et al., 2004; 2006). Karam et al. (2007) obtiveram produtividade de massa seca de $20.000 \mathrm{~kg} \mathrm{ha}^{-1} \mathrm{em}$ trabalho conduzido sob irrigação.

O girassol é uma planta que se adapta a diversas condições edafoclimáticas porém sua necessidade hídrica e os coeficientes de cultura nos diferentes estádios fenológicos, ainda não estão perfeitamente definidas, havendo informações que indicam desde $200 \mathrm{~mm}$ até mais de $900 \mathrm{~mm}$ por ciclo (Sentelhas \& Ungaro, 1998; Tyagi et al., 2000; Karam et al., 2007).

Para realizar o manejo de irrigação, pesquisadores da FAO (Food and Agriculture Organization) recomendam valores de coeficientes de cultura estabelecidos por Doorembos \& Kassam (1994). Em alguns trabalhos os valores determinados por pesquisadores da FAO apresentaram os melhores resultados (Gomes, 2005; Karam et al., 2007; Gomes et al., 2010); no entanto, em outros casos a máxima produtividade tem sido alcançada por meio de valores de coeficientes de cultura superiores (Tyagi et al., 2000; Silva et al., 2007).

Este trabalho foi realizado com o objetivo de se avaliar o desenvolvimento da cultura e a eficiência de uso da irrigação em produtividades da grãos, óleo e massa seca da cultura do girassol, genótipo Aguará 4, em safra normal, sob lâminas de irrigação embasadas na adoção de diferentes coeficientes de cultura.

\section{Material E MÉTODOS}

O trabalho foi realizado no Campus Regional de Umuarama, extensão da Universidade Estadual de Maringá, localizado no Noroeste do estado do Paraná, em altitude de $430 \mathrm{~m}$, latitude $23^{\circ} 47^{\prime} 55^{\prime \prime}$ Sul e longitude 53 $18^{\prime} 48^{\prime \prime}$ Oeste. Segundo a classificação de Köppen, a região apresenta clima Cfa (sem estação seca definida e com temperatura do mês mais quente superior a $22^{\circ} \mathrm{C}$ ).

O solo da área é classificado como Latossolo Vermelho distrófico (EMBRAPA, 2006). De acordo com a análise granulométrica da camada de 0-0,20 m de profundidade, o solo da área experimental possui $83 \%$ de areia, $5 \%$ de silte e $12 \%$ de argila. As densidades do solo nas camadas de 0-0,20 e 0,20-0,40 $\mathrm{m}$ apresentaram valores iguais a 1,43 e $1,53 \mathrm{~kg} \mathrm{dm}^{-3}$, respectivamente. Os valores da análise química do solo referente à profundidade de $0-0,20 \mathrm{~m}$, se encontram na Tabela 1 .

Tabela 1. Análise química do solo na camada de 0-0,20 $\mathrm{m}$ do experimento com girassol irrigado

\begin{tabular}{ccccccc}
\hline $\mathbf{p H}$ & $\mathbf{P}$ & $\mathbf{H}^{+}+\left.\mathbf{A}\right|^{3+}$ & $\mathbf{A l}^{3+}$ & $\mathbf{C a}^{2+}$ & $\mathbf{M g}^{2+}$ & $\mathbf{K}^{+}$ \\
\cline { 3 - 7 }$\left(\mathrm{CaCl}_{2}\right)$ & $\mathbf{m g ~ d m}^{-3}$ & \multicolumn{5}{c}{$\mathbf{c m o l}_{\mathbf{c}} \mathbf{d m}^{-3}$} \\
5,4 & 20,80 & 2,94 & 0 & 4,71 & 1,42 & 0,26 \\
\hline
\end{tabular}

O delineamento experimental utilizado foi em blocos casualizados, com cinco tratamentos e quatro repetições, compondo 20 parcelas, em que quatro tratamentos recebiam diferentes lâminas de água e a testemunha apenas água das chuvas.

As parcelas irrigadas continham quatro microaspersores, um em cada canto, a 1,5 m da superfície do solo. A intensidade de precipitação determinada in loco por meio de instalação de coletores nos centros das parcelas, foi de $8,66 \mathrm{~mm} \mathrm{~h}^{-1}$.

Cada parcela possuía $9 \mathrm{~m}^{2}(3 \times 3 \mathrm{~m})$, com $0,6 \mathrm{~m}$ entre linhas e $0,2 \mathrm{~m}$ entre plantas. As parcelas foram compostas de cinco linhas com 15 plantas cada uma. As duas linhas extremas e as duas últimas plantas de cada linha foram consideradas bordaduras. As parcelas estavam distantes $3 \mathrm{~m}$ umas das outras.

O preparo do solo foi feito por meio de aração e duas gradagens, incorporando $1.000 \mathrm{~kg} \mathrm{ha}^{-1}$ de calcário dolomítico (PRNT 100\%). A semeadura foi realizada 30 dias após o preparo do solo, no dia 27 outubro de 2008, utilizando-se sementes de girassol da cultivar Aguará 4 (ciclo normal). Na adubação de semeadura se aplicaram $300 \mathrm{~kg} \mathrm{ha}^{-1}$ da fórmula 0-20-20 mais $1 \mathrm{~kg} \mathrm{ha}^{-1}$ de boro, na forma de bórax; após 40 dias efetuou-se a adubação de cobertura utilizando-se $50 \mathrm{~kg} \mathrm{ha}^{-1}$ de nitrogênio na forma de uréia.

Todos os tratamentos receberam $30 \mathrm{~mm}$ de irrigação de estabelecimento, elevando o solo à capacidade de campo, aplicado em duas vezes, $15 \mathrm{~mm}$ antes e $15 \mathrm{~mm}$ após semeadura. O manejo da irrigação foi realizado de forma suplementar, por meio de balanço hídrico simplificado, três vezes por semana, nas segundas, quartas e sextas-feiras.

Os valores de precipitação total $(\mathrm{P})$ e evapotranspiração de referência (ETo) foram determinados diariamente, utilizando- 
se da Estação Agrometeorológica do Campus, equipada com anemômetro, termohigrógrafo, tanque classe A e pluviômetro. A evapotranspiração da cultura (ETc) foi estimada a partir do produto da evapotranspiração de referência (ETo) pelo coeficiente de cultura (kc).

A lâmina de irrigação foi estimada pela diferença entre a evapotranspiração da cultura e a precipitação efetiva (LI = ETc - Pe). Por se tratar de solo com lençol freático profundo, desprezou-se a ocorrência de ascensão capilar. Para P $<$ ETc, considerou-se $\mathrm{Pe}=\mathrm{P}$. Para $\mathrm{P} \geq \mathrm{ETc}, \mathrm{Pe}=\mathrm{LI}$, descontando-se as possíveis perdas por escoamento superficial ou drenagem profunda.

A testemunha (L0) recebeu apenas a irrigação de estabelecimento. No tratamento 2 (L2) adotou-se o limite inferior dos valores de kc propostos por Doorembos \& Kassam (1994); para os tratamentos 1, 3 e 4 (L1, L3 e L4) foram adotados, em relação a L2 (1 ETc), valores de kc 50\% abaixo (0,5 ETc), 50\% (1,5 ETc) e $100 \%$ acima (2 ETc), respectivamente. Os valores de coeficientes de cultura utilizados nos diferentes tratamentos irrigados se encontram na Tabela 2.

Tabela 2. Coeficientes de cultura utilizados no girassol em diferentes fases fenológicas de tratamentos irrigados

\begin{tabular}{cccccc}
\hline Tratamentos & Fase 1 & Fase 2 & Fase 3 & Fase 4 & Fase 5 \\
L1 & 0,15 & 0,35 & 0,50 & 0,35 & 0,15 \\
L2 & 0,30 & 0,70 & 1,00 & 0,70 & 0,30 \\
L3 & 0,45 & 1,05 & 1,50 & 1,05 & 0,45 \\
L4 & 0,60 & 1,40 & 2,00 & 1,40 & 0,60 \\
\hline
\end{tabular}

Estabeleceu-se para primeira fase (F1 - estabelecimento) um período de 15 dias. Considerou-se como segunda fase (F2 desenvolvimento vegetativo) o período de 15 dias após semeadura (DAS) até o estádio R4 (abertura da inflorescência e surgimento da cor amarela). A terceira fase (F3 - florescimento) foi considerada do estádio R4 ao R6 (antese completa). Do estádio fenológico R6 ao R8 (dorso do capítulo amarelado e brácteas verdes) considerou-se como quarta fase (F4 frutificação). Do estádio R8 ao R9 (dorso do capítulo e brácteas amareladas) considerou-se como quinta fase (F5 - maturação). A partir da quinta fase (R9) a irrigação foi suspensa até atingir o ponto de colheita. Os estádios foram identificados conforme Castro \& Farias (2005).

Durante o período experimental a temperatura média foi de $25,1^{\circ} \mathrm{C}$ permanecendo, a maior parte do tempo, entre 20 e $30^{\circ} \mathrm{C}$. A umidade relativa média foi de $66,8 \%$ variando de 38,2 a $98,5 \%$. A chuva acumulada no período foi de $454 \mathrm{~mm}$. As lâminas precipitadas na forma de chuva, a temperatura e umidade relativa observadas durante a realização do experimento, podem ser visualizadas na Figura 1.

Os tratamentos L1, L2, L3 e L4 receberam lâminas de irrigação iguais a 99,5, 204,1, 308,6 e 413,3 mm, respectivamente. $\mathrm{Na}$ Tabela 3 se encontram os valores de chuva e lâminas de irrigação nas diferentes fases fenológicas. Ressalta-se que durante a fase 1 não se irrigou a cultura em função da maior ocorrência de chuvas no período.

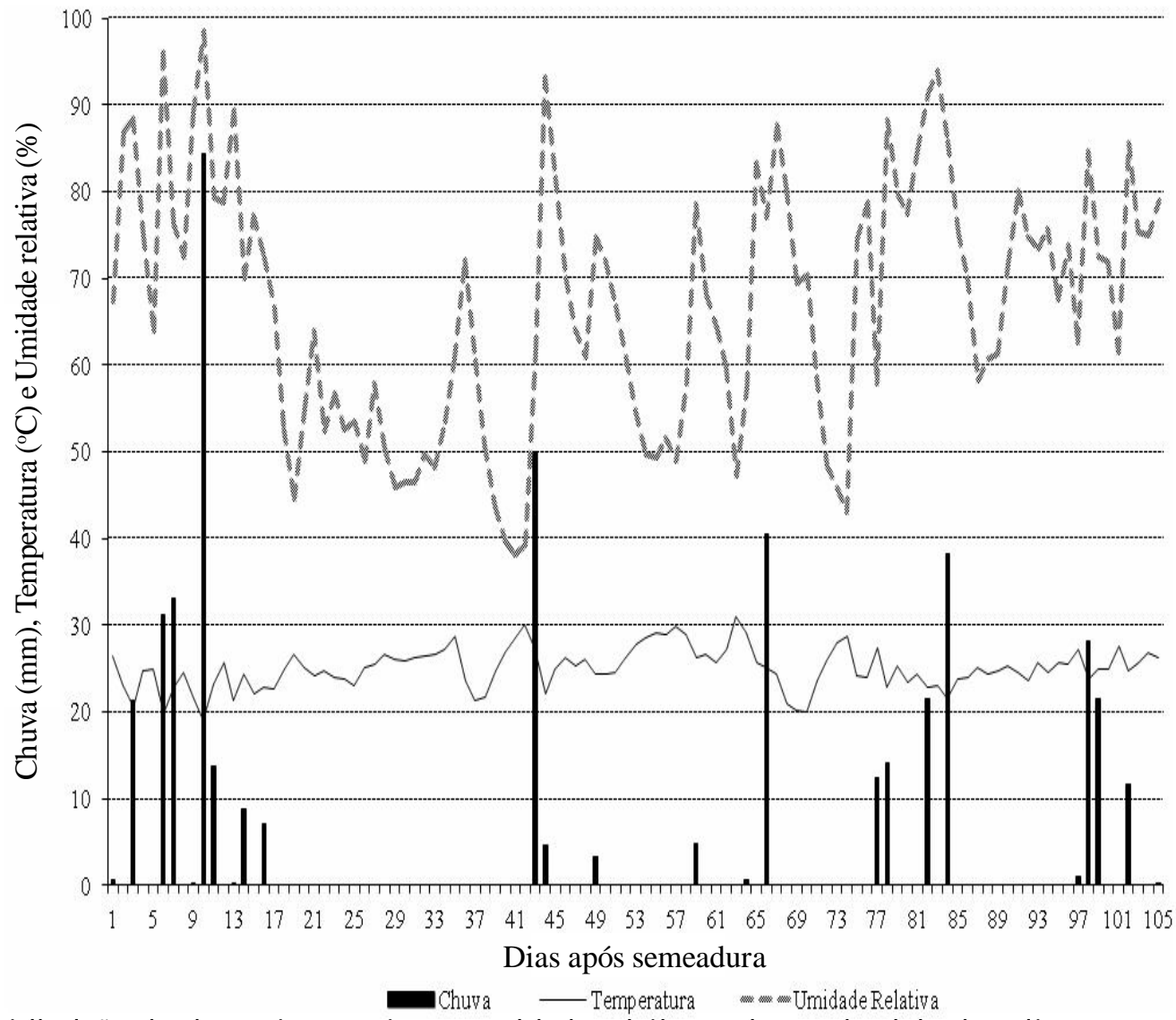

Figura 1. Distribuiçào da chuva, temperatura e umidade relativa ao Iongo do ciclo da cultura e nas diterentes fases fenológicas do girassol 
Tabela 3. Chuva e lâminas de irrigação aplicadas nas diferentes fases fenológicas da cultura do girassol

\begin{tabular}{|c|c|c|c|c|c|c|c|}
\hline \multirow{2}{*}{ Fases fenológicas } & \multirow{2}{*}{ Período (DAS) } & \multirow{2}{*}{$\begin{array}{l}\text { Chuva } \\
\text { (mm) }\end{array}$} & \multirow{2}{*}{ Eventos de irrigação } & \multicolumn{4}{|c|}{ Lâminas de irrigação (mm) } \\
\hline & & & & L1 & L2 & L3 & L4 \\
\hline 1 & $0-15$ & 194,0 & 0 & 0 & 0 & 0 & 0 \\
\hline 2 & $16-61$ & 70,1 & 14 & 61,8 & 127,0 & 192,2 & 257,3 \\
\hline 3 & $62-74$ & 41,0 & 5 & 25,8 & 52,2 & 78,6 & 105,0 \\
\hline 4 & $75-89$ & 86,2 & 2 & 8,3 & 16,7 & 25,0 & 33,6 \\
\hline \multirow[t]{2}{*}{5} & $90-106$ & 62,7 & 2 & 3,6 & 8,2 & 12,8 & 17,4 \\
\hline & Total & 454 & 23 & 99,5 & 204,1 & 308,6 & 413,3 \\
\hline
\end{tabular}

Durante o experimento, duas plantas por parcela foram coletadas das fileiras extremas da área útil ( $2^{\mathrm{a}} \mathrm{e} 4^{\mathrm{a}}$ linha) nos estádios R1 (emissão do broto floral), R4, R6 e R8. Determinaram-se, imediatamente após a coleta, os componentes morfológicos altura de planta (AP), diâmetro de caule (DC) e massa seca da planta inteira (MS).

No final do ciclo (R9), em 10 de fevereiro de 2009, coletaramse, da fileira central ( $3^{\mathrm{a}}$ linha), seis plantas por parcela e se determinaram, além dos componentes morfológicos AP, MS e DC, os componentes de produção produtividades de grãos (PG) e óleo (PO), teor de óleo (TO), diâmetro de capítulo (DCAP) e massa de cem sementes (M100).

A AP foi determinada após o corte das planta, rente ao solo e obtida por meio de uma trena de resolução igual a $0,1 \mathrm{~cm}$, a qual também foi utilizada para medir o DCAP.

A MS foi obtida após $72 \mathrm{~h}$ de permanência da planta inteira em estufa a $65^{\circ} \mathrm{C}$ e com a utilização de uma balança de resolução igual a $0,01 \mathrm{~g}$; no estádio final (R9), a MS foi chamada PMS (produtividade de massa seca).

O DC sempre foi medido entre o segundo e o terceiro par de folhas, utilizando-se um paquímetro digital de resolução igual a $0,01 \mathrm{~mm}$.

A PG e a M100 foram obtidas com a da pesagem em balança de resolução de $0,01 \mathrm{~g}$ e corrigidas por meio de um determinador de umidade de sementes a $13 \%$.

Na determinação de TO as amostras foram trituradas em um moinho de facas, pesadas e encaminhadas para um extrator do tipo Soxhlet, onde permaneceram em refluxo com éter pelo tempo de $6 \mathrm{~h}$; após a extração, as amostras foram acondicionadas em estufa a $70{ }^{\circ} \mathrm{C}$ por $30 \mathrm{~min}$ e em seguida levadas para um dessecador por mais 30 min e novamente pesadas.

Ao final de cada fase os componentes de produção foram submetidos à análise de variância e quando constatadas efeitos significativos foi feito à análise de regressão. O desenvolvimento da cultura ao longo do ciclo foi avaliado por meio de análises descritivas dos componentes morfológicos AP, DC e MS.

Após o experimento determinou-se a eficiência de uso da irrigação, conforme Gordon et al. (1995):

$$
\mathrm{EUI}=\frac{\left(\mathrm{P}_{\mathrm{i}}-\mathrm{P}_{0}\right)}{\mathrm{L}}
$$

em que:

EUI - eficiência de uso da irrigação, $\mathrm{kg} \mathrm{ha}^{-1} \mathrm{~mm}^{-1}$

$\mathrm{P}_{\mathrm{i}}$ - produtividade do tratamento irrigado, $\mathrm{kg} \mathrm{ha}^{-1}$

$\mathrm{P}_{0}$ - produtividade do tratamento sem irrigação, $\mathrm{kg} \mathrm{ha}^{-1}$

L - lâmina de irrigação, mm

\section{RESULTADOS E DISCUSSÃO}

Apesar da precipitação total de $454 \mathrm{~mm}$ e da ocorrência de precipitações em todas as fases, a distribuição não foi uniforme (Figura 1). Na fase 2 ( 16 a 61 DAS) houve um período de 26 dias sem chuva, dos 17 aos 42 DAS, necessitando de 14 eventos de irrigação (Tabela 2). Na fase 3 (62 a 74 DAS) a precipitação ocorreu em um único evento, aos 66 DAS, necessitando de 5 eventos de irrigação (Tabela 2).

A chuva ocorreu com maior frequência na fase 1 (Figura 1), dispensando o uso da irrigação nesta fase (Tabela 3). Nas fases 4 e 5, a distribuição das chuvas foi melhor, fazendo com que apenas 4 eventos de irrigação fossem suficientes.

Constataram-se respostas significativas das alturas de plantas (AP) em função da irrigação, em todas as fases analisadas (Figura 2). Analisando a Figura 2 (A, B e D), observase que a altura de plantas aumentou linearmente em função da lâmina de água fornecida. Tendência similar também foi detectada por Silva et al. (2007) ao estudar a aplicação de lâminas de água e doses de boro na cultura do girassol.

As respostas quadráticas de AP nos estádios R6 e R9 são consequência da proximidade de valores entre os tratamentos L3 e L4. Por ocasião da última coleta as plantas do tratamento L4 apresentaram altura média de $184,9 \mathrm{~cm}$ enquanto as plantas do tratamento L3 apresentaram altura média de $181,7 \mathrm{~cm}$. A altura média no tratamento referência (L2) foi $172,4 \mathrm{~cm}$ e no tratamento sem irrigação (L0) $132,1 \mathrm{~cm}$.

Vários autores encontraram resultados semelhantes. Por exemplo, em Limeira, SP, Gomes (2005) obteve, utilizando a cultivar M-742, alturas médias de planta (AP) iguais a 180 e 130 $\mathrm{cm}$, com e sem irrigação, respectivamente. Na Turquia, Goksoy et al. (2004), obtiveram, utilizando a cultivar Sanbro, AP iguais a 154,2 e 145,4 cm, com e sem irrigação, respectivamente. Silva et al. (2007) obtiveram em Lavras, MG, utilizando o genótipo H 250, AP iguais a 151 e $128 \mathrm{~cm}$, com e sem irrigação, respectivamente.

O maior incremento em AP ocorreu do estádio R1 ao R4 e a partir do estádio R6 o incremento diminuiu sensivelmente (Figura 2F), podendo ser explicado pelo processo de redistribuição de assimilados da fitomassa (fonte) para a produção de aquênios (dreno).

O acréscimo de altura do estádio R6 ao R9 (fases 4 e 5) foi de apenas $5 \mathrm{~cm}$ no tratamento L4; no estádio R6 a AP era de 177,9 $\mathrm{cm}$. Comportamento semelhante foi observado por Acosta (2009), em experimento de girassol com irrigação ao observar, a partir desse estádio, um acréscimo de apenas $4 \mathrm{~cm}$, passando de 169 para $173 \mathrm{~cm}$. 


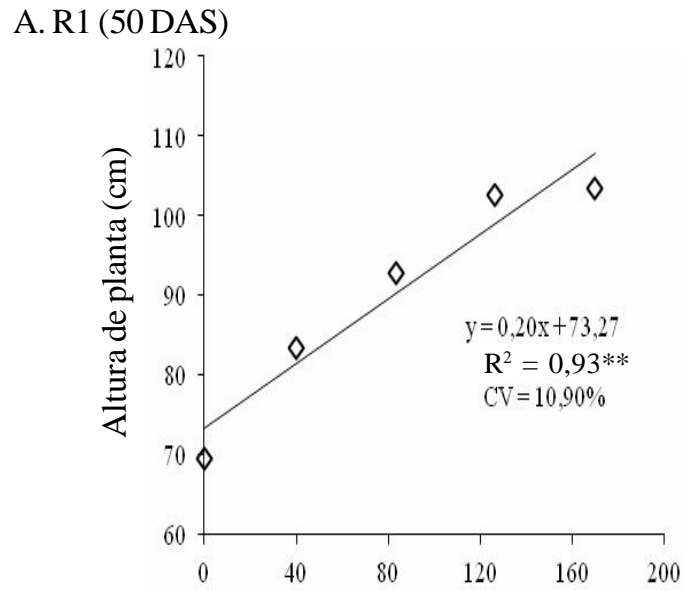

C. R6 (74 DAS)

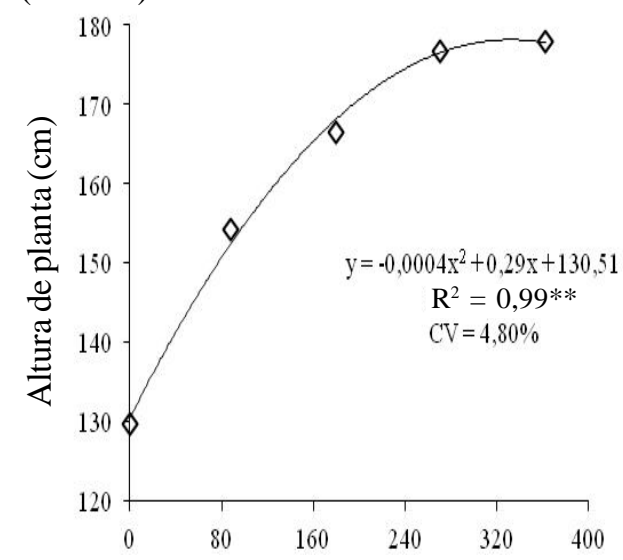

E. R9 (106 DAS)

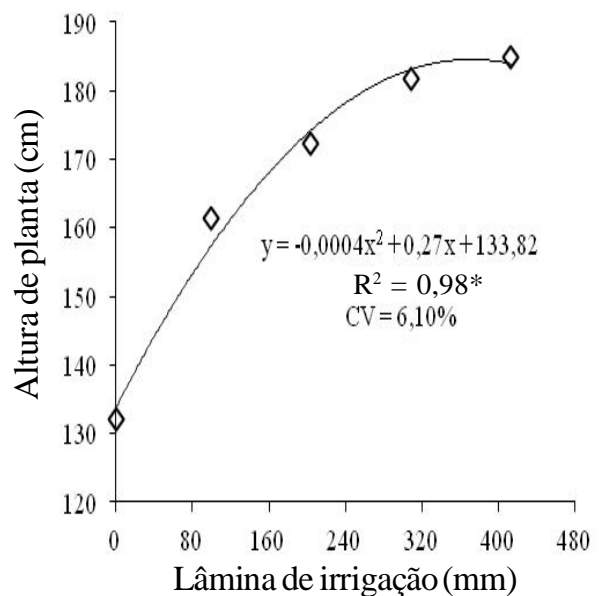

B. R4 (61 DAS)

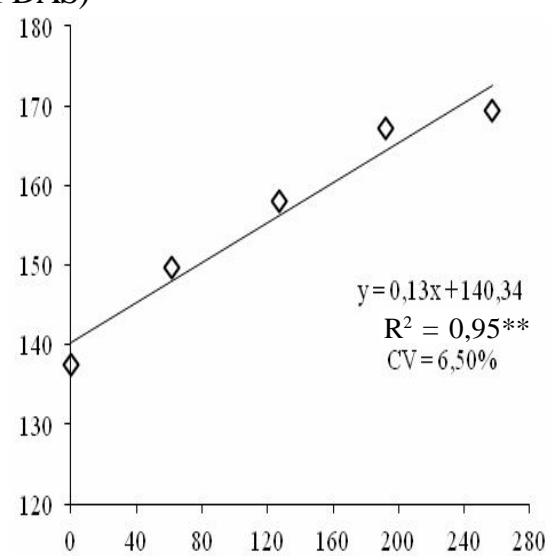

D. R8 (89 DAS)

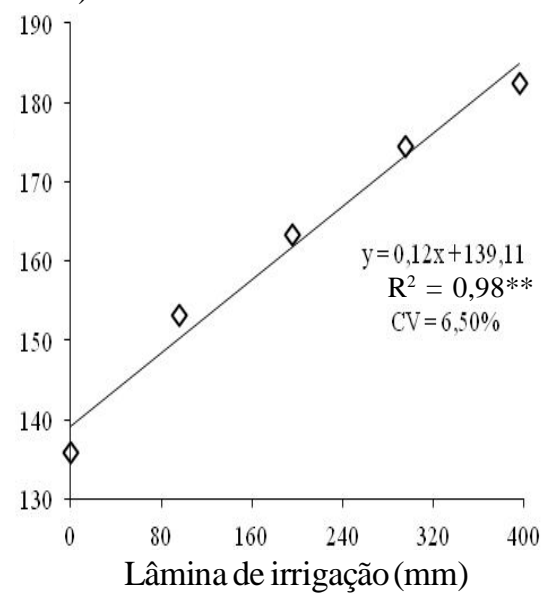

F.

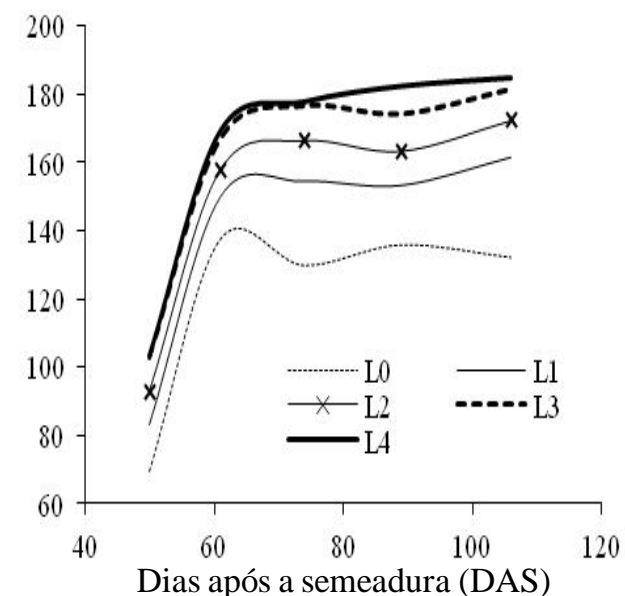

Figura 2. Altura de planta de girassol em função da irrigação em diferentes estádios fenológicos (A, B, C, D e E) e em função de dias após semeadura (F)

O diâmetro de caule (DC) respondeu, de maneira linear, à irrigação, em todos os estádios analisados (Figura 3). Segundo Biscaro et al. (2008) o diâmetro de caule é uma característica morfológica importante que atua na resistência ao acamamento.

No final do ciclo para os tratamentos $\mathrm{L} 0$ e L4, os diâmetros de caule foram iguais a 15,9 e 22,7 mm, respectivamente. Em experimento conduzido por Backes et al. (2008), sem irrigação, porém com distribuição regular das chuvas, a cultivar Aguará 4 obteve diâmetro de caule superior, igual a $24,4 \mathrm{~mm}$.

Campos et al. (2010) também verificaram que a reposição de água favoreceu o aumento do diâmetro caulinar do girassol
Embrapa 122/V-2000, sendo visualizada a estabilização do diâmetro a partir dos 60 DAS. Neste trabalho e apesar do comportamento adverso (Figura $3 \mathrm{~F}$ ), percebe-se que o maior incremento de DC ocorreu até o estádio R4 (62 DAS).

A massa seca (MS) respondeu, de forma linear, à irrigação (Figura 4), exceto no estádio R4 (Figura 4B). A não significância neste estádio é corroborada por meio da Figura 4F, podendose observar que aos 61 DAS ocorre aproximação do acúmulo de massa seca entre os tratamentos.

Segundo Toureiro et al. (2007), após restrição hídrica durante as fases iniciais (estabelecimento e desenvolvimento vegetativo), 
A. R1 (50 DAS)

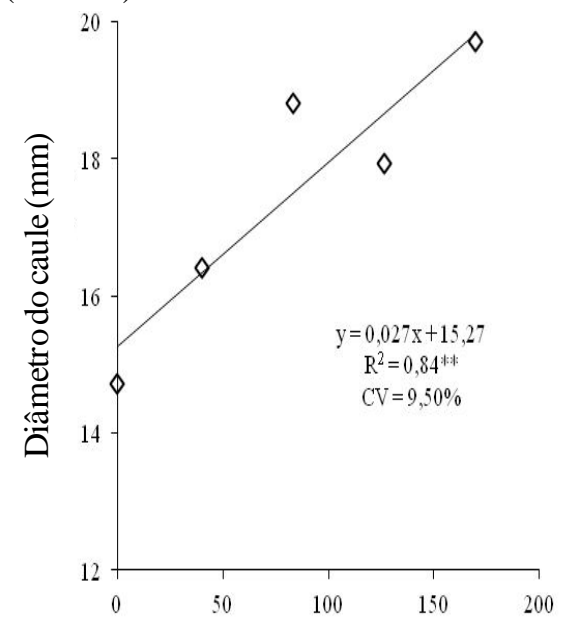

C. R6 (74 DAS)

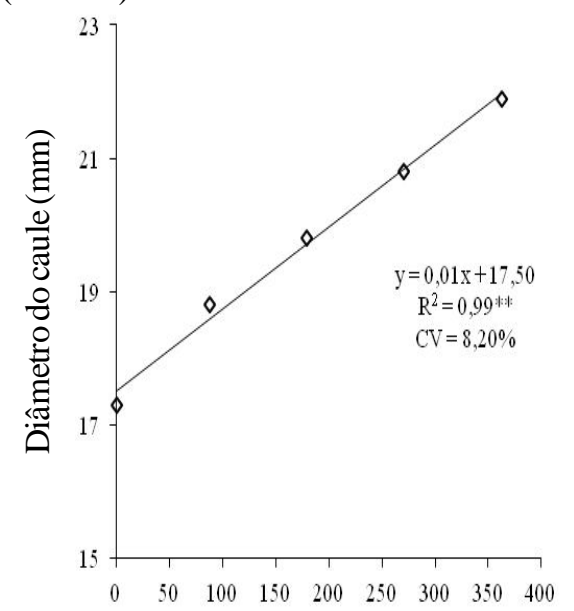

E. R9 (106DAS)

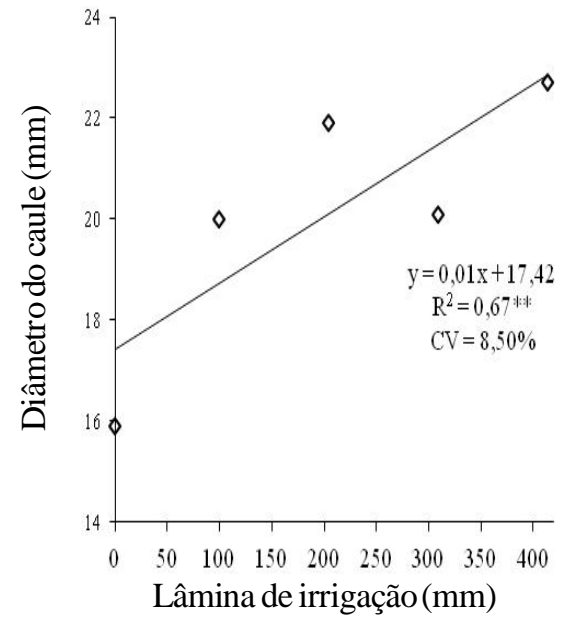

B. R4 (61 DAS)

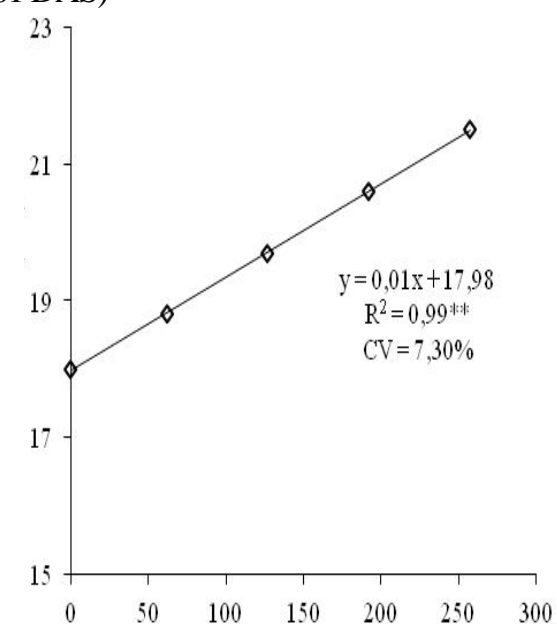

D. R8 (89 DAS)

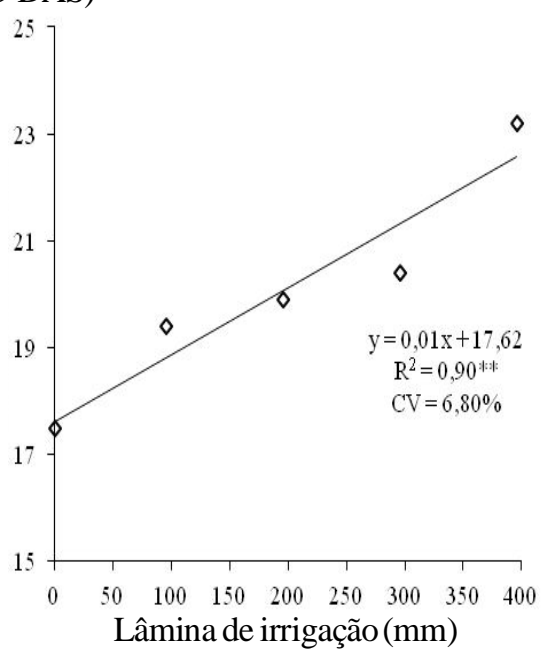

F.

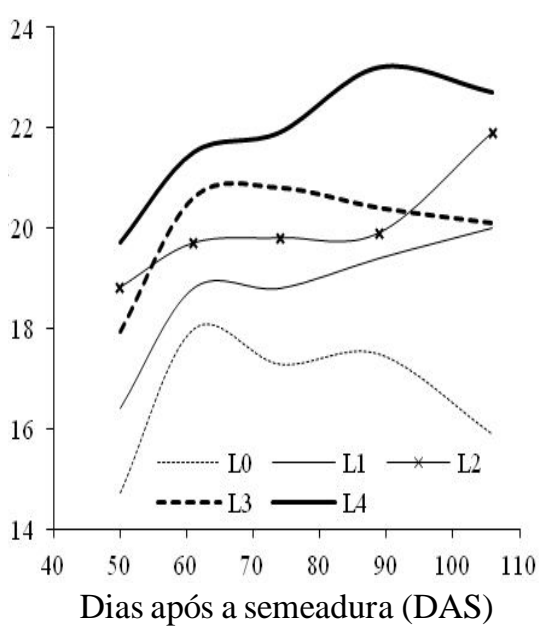

Figura 3. $D$ iâmetro de caule de girassol em função da irrigação em diferentes estádios fenológicos ( $A, B, C, D$ e E) e em função de dias após semeadura (F)

o girassol tende a aprofundar as raízes, recuperando parcialmente o desenvolvimento inicialmente prejudicado.

No final do ciclo a produtividade de MS atingiu o valor de $17.542 \mathrm{~kg} \mathrm{ha}^{-1}$ no tratamento L4, $60 \%$ maior que no tratamento L0, igual a $10.992 \mathrm{~kg} \mathrm{ha}^{-1}$. O resultado obtido se aproxima do encontrado por Karam et al. (2007), em experimento sob irrigação conduzido no Líbano, igual a $20.000 \mathrm{~kg} \mathrm{ha}^{-1}$. Mello et al. (2006), em Santa Maria, RS, corroboram o resultado obtido em L0, uma vez que obtiveram, em experimento sem irrigação, PMS da ordem de $11.000 \mathrm{~kg} \mathrm{ha}^{-1}$ com as cultivares M-734 e BRS 191.

Segundo Castro \& Farias (2005) é comum se obter valores de MS superiores a $14.000 \mathrm{~kg} \mathrm{ha}^{-1}$ em cultivos de girassol sob irrigação; em L2 a produtividade de MS foi de $15.608 \mathrm{~kg} \mathrm{ha}^{-1}$, $42 \%$ maior que a obtida em LO. 


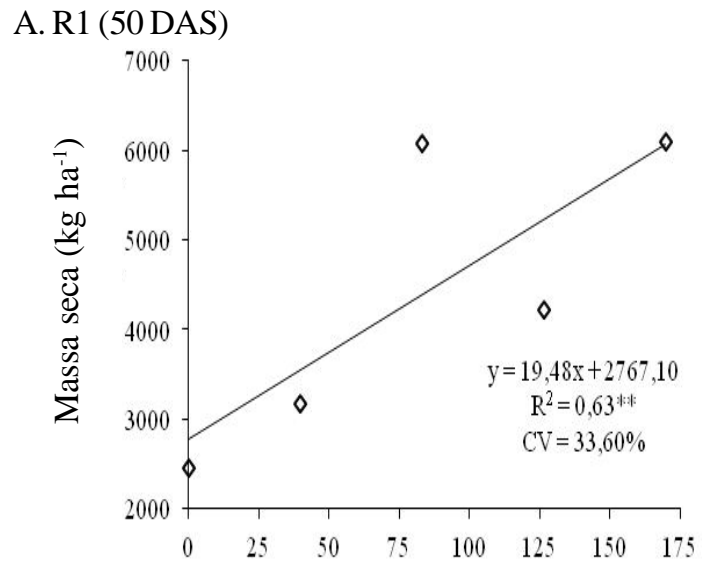

C. R6 (74 DAS)

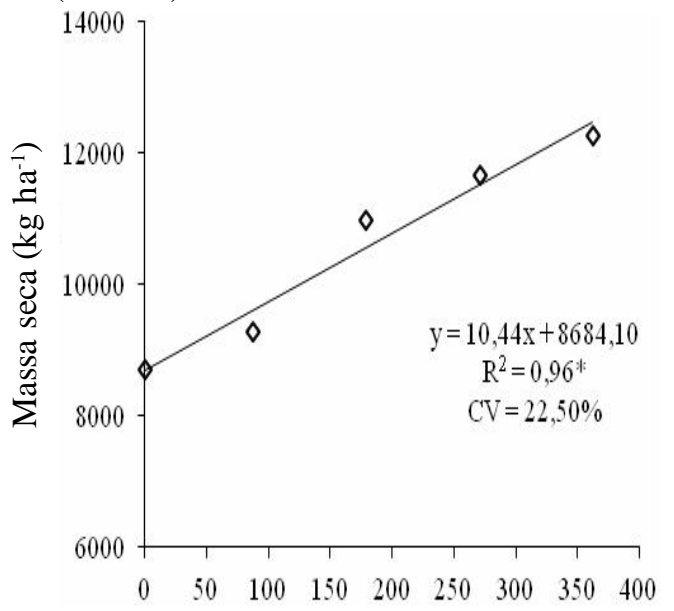

E. R9 (106 DAS)

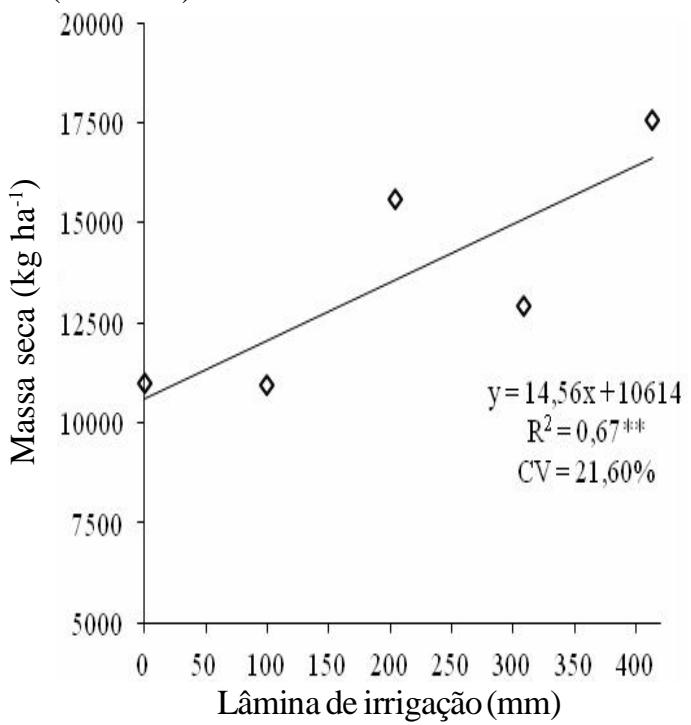

B. R4 (61 DAS)

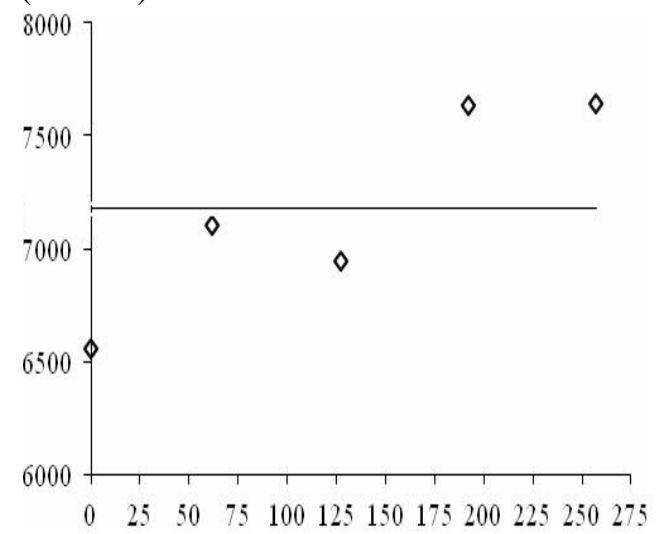

D. R8 (89 DAS)

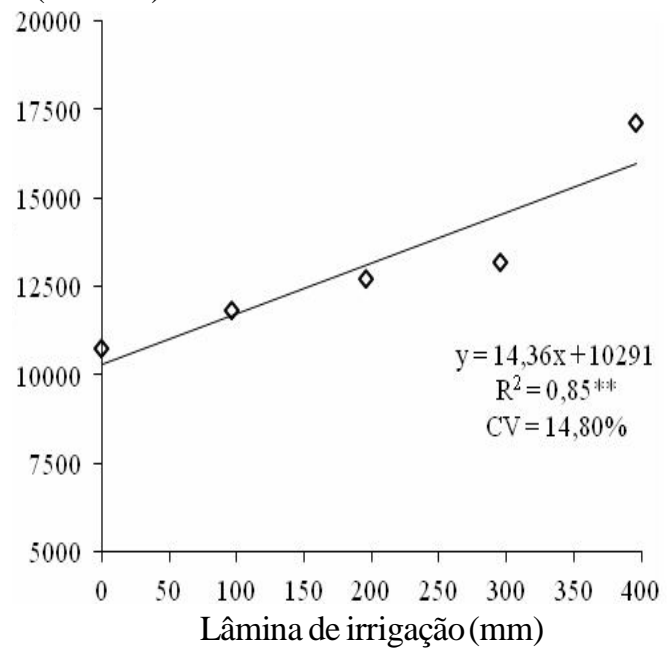

F.

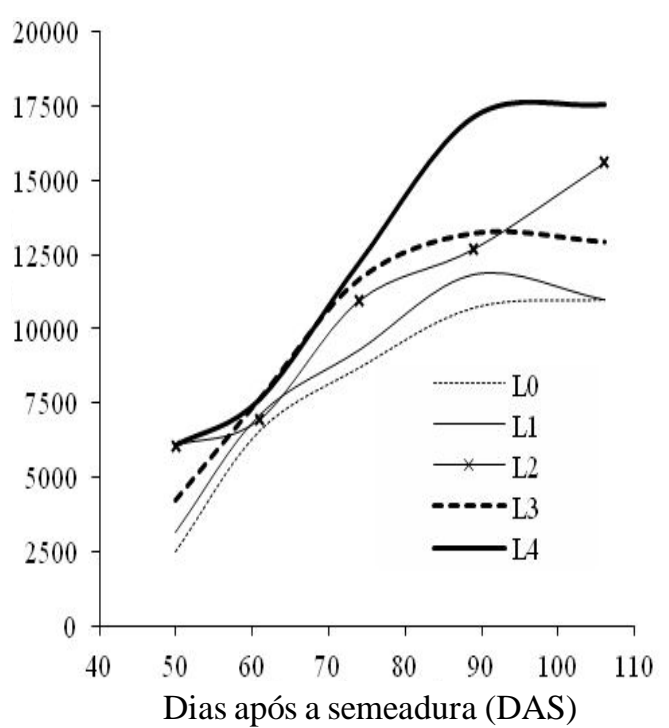

Figura 4. M assa seca de girassol em função da irrigação em diferentes estádios fenológicos ( $A, B, C, D$ e E) e em função de dias após semeadura (F)

A partir do estádio R8 a produção de MS se encontrava praticamente estabilizada, em função da senescência da cultura (Figura 4F). Caso o objetivo seja a produção de silagem pode-se considera, então, a possibilidade desse momento como final de ciclo. No entanto, não há consenso sobre a época ideal pois o teor de proteína tende a aumentar quando a colheita é realizada noestádio R9, apesar da diminuição da digestibilidade (Rezende et al., 2007).
A produtividade de grãos (PG) apresentou comportamento linear (Figura 5), com $4.788 \mathrm{~kg} \mathrm{ha}^{-1}$ no tratamento sem irrigação (L0) e $6.963 \mathrm{~kg} \mathrm{ha}^{-1}$ no tratamento com aplicação da maior lâmina de irrigação (L4), ou seja, 45,4\% maior.

No tratamento L2 a PG de $6.304 \mathrm{~kg} \mathrm{ha}^{-1}$ foi $31,7 \%$ superior em relação à PG em L0. Alguns trabalhos têm demonstrado que o aumento de produção da cultura do girassol em função da 


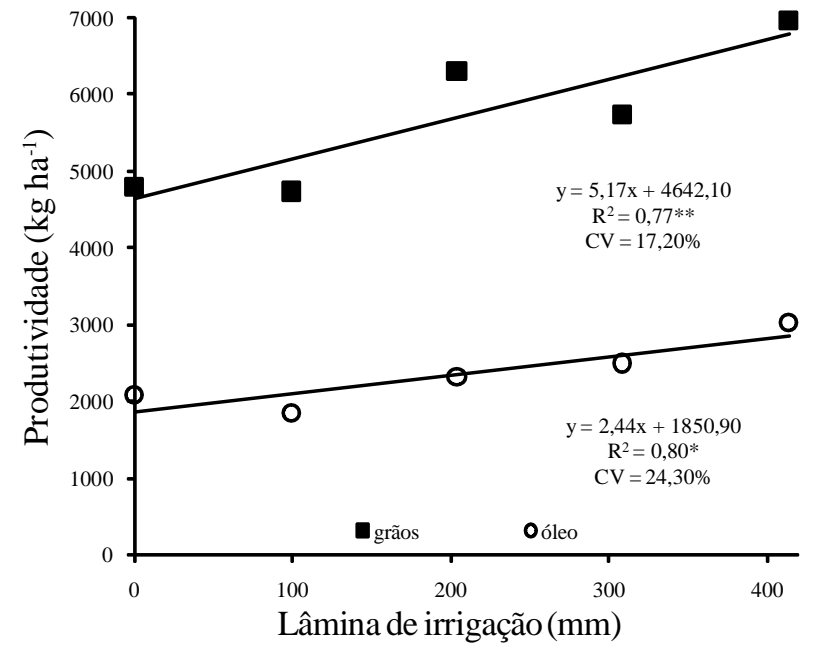

Figura 5. Produtividades de grãos e óleo da cultura do girassol em função da lâmina de irrigação

irrigação varia de 30 a 100\%, com incrementos acima de $70 \%$ em regiões de clima semiárido (Fragella et al., 2002; Goksoy et al. 2004; Castro et al., 2006; Silva et al., 2007; Anastasi et al., 2010).

A PG foi superior às obtidas por Silva et al. (2007) utilizando a cultivar $\mathrm{H}-250$ e Biscaro et al. (2008) utilizando a cultivar H358 , ambos sob irrigação, conduzidos no Brasil em cultivo de segunda safra (safrinha), iguais a 2.860 e $2.100 \mathrm{~kg} \mathrm{ha}^{-1}$, respectivamente.

Em experimentos realizados em outros países em que o girassol não é cultivado como cultura de segunda safra, a produtividade de grãos sob irrigação tem superado a 4.000 $\mathrm{kg} \mathrm{ha}^{-1}$ (Goksoy et al. 2004; Karam et al., 2007; Anastasi et al., 2010).

A produtividade obtida neste trabalho por meio do tratamento L2 se aproxima do resultado obtido por Karam et al. (2007), em experimento conduzido no Líbano, que obtiveram sob irrigação, em umidade de grãos de base úmida equivalente (13\%), $5.800 \mathrm{~kg} \mathrm{ha}^{-1}$.

Observa-se, na Tabela 4, que a massa seca (MS) apresentou a maior correlação com a produtividade de grãos $(\mathrm{PG})(\mathrm{r}=0,93)$, seguida do diâmetro de capítulo (DCAP) $(\mathrm{r}=0,77)$ e diâmetro de caule (DC) $(\mathrm{r}=0,73)$. Karam et al. (2007) também verificaram que os tratamentos com maior acúmulo de MS resultaram em maiores produtividades de grãos.

Tabela 4. Correlações entre componentes morfológicos e de produção da cultura do girassol

\begin{tabular}{ccccccc}
\hline & AP & MS & DC & T0 & DCAP & M100 \\
MS & 0,59 & & & & & \\
DC & 0,81 & 0,79 & & & & \\
TO & 0,07 & 0,14 & 0,26 & & & \\
DCAP & 0,71 & 0,72 & 0,89 & 0,30 & & \\
M100 & 0,14 & 0,43 & 0,03 & 0,12 & 0,08 & \\
PROD & 0,57 & 0,93 & 0,73 & 0,17 & 0,77 & 0,52 \\
\hline
\end{tabular}

AP - altura de planta; MS - massa seca; DC- diâmetro de caule (DC) e de produção; TO - teor de óleo; DCAP - diâmetro de capítulo; PG - produtividade de grãos

Não houve diferença significativa entre os tratamentos em relação ao teor de óleo (TO), com valor médio de 41,5\% (Figura 6A), resultado corroborado por Goksoy et al. (2004), em razão de não terem encontrado, em seu trabalho realizado na Turquia, diferenças significativas no TO da cultura do girassol, em função do manejo de irrigação, com valor médio de $45,1 \%$.

Mesmo assim, em trabalhos conduzidos na Itália por Fragella et al. (2002) e Anastasi et al. (2010), os incrementos devidos à irrigação, foram significativos. No primeiro caso os autores obtiveram TO de 50,7\% sob irrigação enquanto sem irrigação o teor de óleo foi 47,9\%; no segundo caso, na maior lâmina (igual a 1 ETc) o TO foi de 50,4\%, e no tratamento sem irrigação, TO foi de $44,7 \%$.

O TO é afetado principalmente pelo déficit hídrico durante o período de enchimento dos aquênios, fase 4 (Castro \& Farias, 2005). Nesta fase ocorreram quatro eventos de chuvas (Figura 1) totalizando uma precipitação de $86,2 \mathrm{~mm}$ (Tabela 3). O balanço hídrico desta fase demonstrou a necessidade de apenas dois eventos de irrigação, passível de ser explicada a não diferença significativa no teor de óleo entre os tratamentos.

A produtividade de óleo ( $\mathrm{PO}$ ) foi proporcional à produtividade de grãos (PG), com comportamento igualmente linear (Figura 5), com $2.086 \mathrm{~kg} \mathrm{ha}^{-1}$ no tratamento L0 e 3.022 $\mathrm{kg} \mathrm{ha}^{-1}$ no tratamento L4. As produtividades podem ser consideradas elevadas em ambos os casos, visto que PO em cultivos de girassol sem irrigação está normalmente compreendida numa faixa de 400 a $1.000 \mathrm{~kg} \mathrm{ha}^{-1}$ enquanto sob irrigação a produtividade geralmente se encontra numa faixa de 700 a $2.200 \mathrm{~kg} \mathrm{ha}^{-1}$ (Fragella et al., 2002; Goksoy et al. 2004; Silva et al., 2007; Anastasi et al., 2010). Há que se ressaltar, no entanto, que nem todos os trabalhos que determinam a produtividade de grãos fazem o mesmo em relação ao óleo.

A massa de 100 sementes (M100) não foi influenciada pela irrigação, com valor médio de 6,55 g (Figura 6B). Silva et al. (2007) corroboram este resultado, pois em experimento conduzido sob lâminas de irrigação também não encontraram diferenças significativas na M100 para a cultivar H250, com valor de 4,12 $\mathrm{g}$.

Contrariamente, Anastasi et al. (2010) observaram, em experimento conduzido sob lâminas de irrigação, diferenças significativas, com valores de M100 iguais 5,35 e 4,14 g para a maior lâmina (igual a 1 ETc) e sem irrigação, respectivamente. Fragella et al. (2002) também constataram diferenças significativas na M100 entre os tratamentos irrigado e sem irrigação iguais, respectivamente, a 4,39 e 3,35 g.

Segundo Castro \& Farias (2005) a diferença de massa entre as sementes normalmente ocorre quando a cultura do girassol é submetida a um déficit hídrico permanente, diferente do verificado no presente trabalho.

A M100 é um componente que apresenta considerável amplitude de valores entre as cultivares. Backes et al. (2008) observaram, conduzindo trabalho de competição de genótipos em cultivo de safrinha e sem irrigação, para 12 cultivares, valores de 3,15 a 7,92 g, com valor igual a 4,67 g para a cultivar Aguará 4 .

O diâmetro de capítulo (DCAP) analisado no final do ciclo (R9) foi influenciado significativamente pela irrigação, apresentando um comportamento quadrático de tendência assintótica (Figura 6C).

O maior valor de DCAP foi obtido por meio da aplicação da maior lâmina (L4), igual 18,7 cm e, sem irrigação (L0) obteve-se o menor valor, igual a $14,3 \mathrm{~cm}$. Gomes (2005) obteve DCAP 
A.

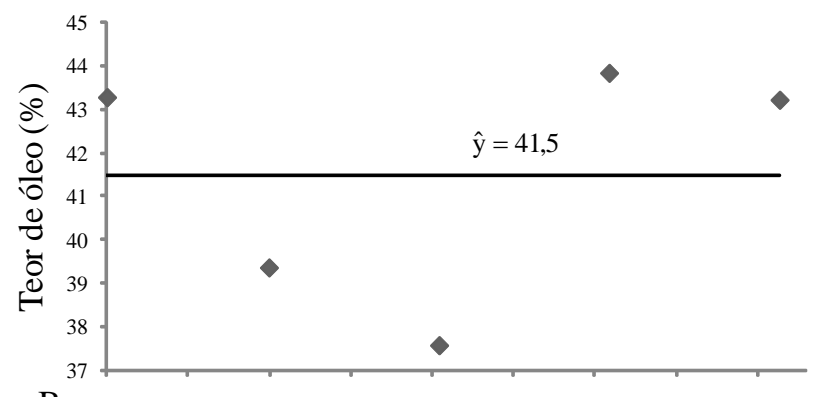

B.

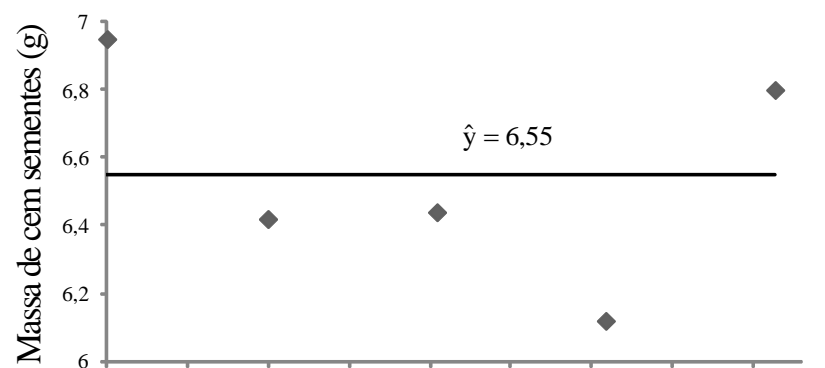

C.

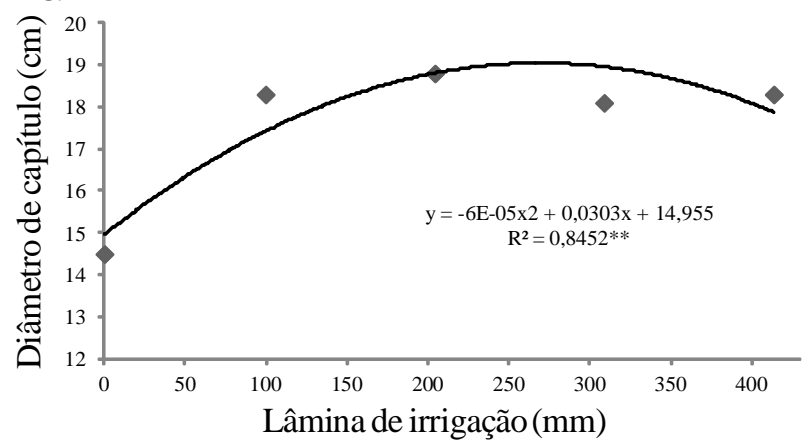

Figura 6. Valores dos componentes de produção teor de óleo (TO), massa de cem sementes (M 100) e diâmetro de capítulo (DCAP) da cultura do girassol em função da lâmina de irrigação

igual $15,9 \mathrm{~cm}$ com irrigação e DCAP igual $13 \mathrm{~cm}$ sem irrigação. Silva et al. (2007) também observaram este comportamento, pois em trabalhos sob lâminas de irrigação, obtiveram sem irrigação e na aplicação da maior lâmina (igual a 1,3 ETc), valores de DCAP iguais a 16,08 e 17,64 cm, respectivamente.

Alguns trabalhos não medem DCAP porém mensuram o número de aquênios por capítulo (NAC) e, segundo Castro \& Farias (2005) são componentes correlacionáveis. Anastasi et al. (2010) e Fragella et al. (2002) obtiveram NAC maiores sob irrigação; no primeiro caso o NAC foi de 1400 com irrigação e 915 sem irrigação e, no segundo caso, 1095 com irrigação 794 sem irrigação.

Neste trabalho DCAP foi o componente que exerceu maior influência na produtividade de massa seca $(r=0,79)$, seguido do DC $(r=0,72)$. Segundo Acosta (2009) esses componentes são realmente os que apresentam as maiores correlações com a PMS.

Apesar das respostas significativas das produtividades de massa seca, grãos e óleo à irrigação, os maiores valores de eficiência de uso da irrigação (EUI) ocorreram com a aplicação da lâmina de referência L2 (1 ETc), respectivamente iguais a 22,62, 7,43 e 3,12 $\mathrm{kg} \mathrm{ha}^{-1} \mathrm{~mm}^{-1}$. As EUIs obtidas em L4 (2 ETc) apresentaram valores da ordem de $70 \%$ de $\mathrm{L} 2$, com $15,84,5,26 \mathrm{e}$ $2,21 \mathrm{~kg} \mathrm{ha}^{-1} \mathrm{~mm}^{-1}$ para massa seca, grãos e óleo, respectivamente e as EUIs em L3 (1,5 ETc) foram iguais a 6,20, 3,04 e 1,28 $\mathrm{kg} \mathrm{ha}^{-1} \mathrm{~mm}^{-1}$ para massa seca, grãos e óleo, respectivamente; em L1 $(0,5 \mathrm{ETc})$ as EUIs foram negativas, iguais a $-0,42,-0,58$ e $-0,25 \mathrm{~kg} \mathrm{ha}^{-1} \mathrm{~mm}^{-1}$ para massa seca, grãos e óleo, respectivamente (Figura 7).

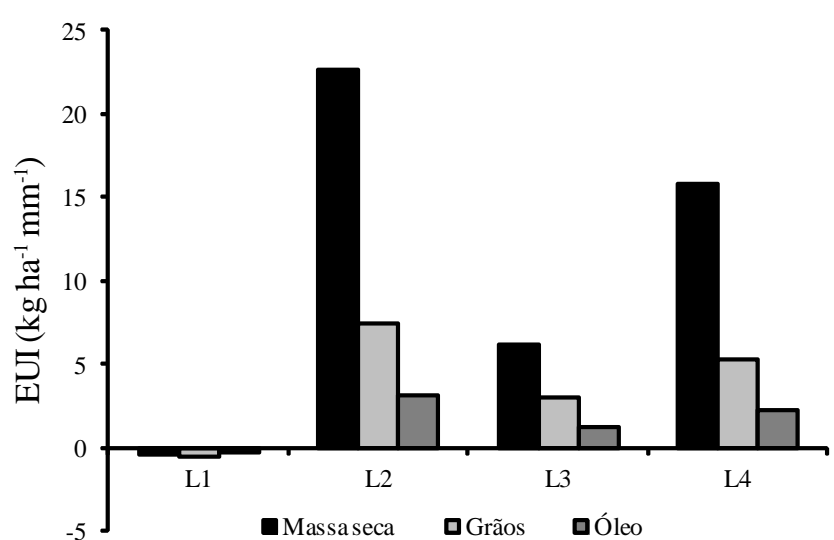

Figura 7. Eficiências de uso da irrigação para produtividades de massa seca, grãos e óleo da cultura do girassol

O resultado obtido é similar ao encontrado por Anastasi et al. (2010) que, trabalhando com a cultura do girassol, obtiveram o maior valor da EUI para grãos sob $1 \mathrm{ETc}$; no entanto, Silva et al. (2007), obtiveram o maior valor da EUI para grãos sob 1,3 ETc; nesses trabalhos os valores encontrados foram iguais a $5,79 \mathrm{e} 2,32 \mathrm{~kg} \mathrm{ha}^{-1} \mathrm{~mm}^{-1}$, respectivamente.

Os incrementos de produtividades (massa seca, grãos e óleo) de L4 em relação a L2 foram da ordem de $10 \%$ enquanto a lâmina de água aplicada foi superior a $100 \%(413,3 \mathrm{~mm}$ em L4 e $204,1 \mathrm{~mm}$ em L2, o que pode ser atribuído ao fato do girassol ser inapto para regular seu consumo de água (Ungaro, 1986)) e explicar os menores valores de EUI em L4.

\section{CONCLUSÕES}

1. A irrigação suplementar favoreceu o desenvolvimento da cultura uma vez que em todas as fases analisadas os menores valores dos componentes morfológicos ocorrem na ausência da irrigação.

2. As produtividades de massa seca, grãos e óleo, respondem de maneira linear à irrigação.

3. A adoção de coeficientes de cultura acima dos recomendados pela FAO diminui a eficiência de uso da irrigação.

4. A irrigação não exerce influência sobre o teor de óleo, sendo a produtividade de óleo proporcional à produtividade de grãos.

\section{LITERATURA CITADA}

Acosta, J. F. Consumo hídrico da cultura do girassol irrigada na região da Chapada do Apodi, RN. Campina Grande: UFCG, 2009. 56p. Dissertação Mestrado 
AGRIANUAL 2008 - Anuário da Agricultura Brasileira. São Paulo: FNP Consultoria e Comércio, 2008. 502p.

Anastasi, U.; Santonoceto, C.; Giuffre, A. M.; Sortino, O.; Abbate, V. Yield performance and grain lipid composition of standard and oleic sunflower as affected by water supply. Field Crops Research, v.119, p.145-153, 2010.

Backes, R. L.; Souza, A. M.; Balbinot Júnior, A. A.; Galotti, G. J. M.; Bavaresco, A. Desempenho de cultivares de girassol em duas épocas de plantio safrinha no Planalto Norte Catarinense. Scientia Agrária, v.9, p.41-48, 2008.

Biscaro, G. A.; Machado, J. R.; Tosta, M. S.; Mendonça, V.; Soratto, R. P.; Carvalho, L. A. Adubação nitrogenada em cobertura no girassol irrigado nas condições de Cassilândia - MS. Ciência e Agrotecnologia, v.32, p.1366-1373, 2008.

Campos, V. B.; Chaves, L. H. G.; Guedes Filho, D. H.; Santos Junior, J. A. Reposição da água de irrigação na cultura do girassol. In: Reunião Brasileira de Fertilidade do Solo e Nutrição de Plantas, 29, 2010, Guarapari. Anais... Viçosa: SBCS, 2010. CD-Rom

Castro, C.; Farias, J. R. B. Ecofisiolgia do girassol. In: Leite, R. M. V. B. C.; Brighenti, A. M.; Castro, C. (ed.) Girassol no Brasil. Londrina: EMBRAPA, 2005. p.163-218.

Castro, C.; Moreira, A.; Oliveira, R. F.; Dechen, A. R. Boro e estresse hídrico na produção do girassol. Ciência e Agrotecnologia, v.30, p.214-220, 2006.

Doorenbos, J.; Kassam, A. H. Efeito da irrigação no rendimento das culturas. Campina Grande: UFPB, 1994. 306p. FAO Irrigação e Drenagem, n.33

EMBRAPA - Empresa Brasileira de Pesquisa Agropecuária. Sistema brasileiro de classificação dos solos. Brasília: EMBRAPA, 2006. 306p.

Fragella, Z.; Rotunno, T.; Tarantino, R.; Caterina, A. C. Changes in seed yield and oil fatty acid composition of high oleic sunflower hybrids in relation to the sowing date and water regime. European Journal of Agronomy, v.17, p.221-230, 2002.

Gomes, E. M. Parâmetros básicos para irrigação sistemática do girassol. Campinas: UNICAMP, 2005. 99p. Tese Doutorado

Gomes, E. P.; Ávila, M. R.; Rickli, E.; Petri, F.; Fedri, G. Desenvolvimento e produtividade do girassol sob lâminas de irrigação em semeadura direta na região do Arenito Caiuá, Estado do Paraná. Irriga, v.15, p.375-385, 2010.

Goksoy, A. T.; Demir, A. O.; Turan, Z. M.; Dagustu, N. Responses of sunûower to full and limited irrigation at different growth stages. Field Crops Research, v.87, p.167$178,2004$.

Gordon, W. B.; Raney, R. J.; Stone, L. R. Irrigation management practices for corn production in north central Kansas. Journal of Soil and Water Conservation, v.50, p.395-398, 1995.

Heckler, J. C. Sorgo e girassol no outono-inverno, em sistema plantio direto, no Mato Grosso do Sul, Brasil. Ciência Rural, v.32, p.517-520, 2002.
Karam, F.; Lahoud, R.; Masaad, R.; Kabalan, R.; Breidi, J.; Chalita, C.; Rouphael, Y. Evapotranspiration, seed yield and water use efûciency of drip irrigated sunûower under full and deûcit irrigation conditions. Agricultural Water Management, v.90, p.213-223, 2007.

Mello, R.; Nornberg, J. L.; Restle, J.; Neumann, M.; Queiroz, A. C.; Costa, P. B.; Magalhães, A. L. R.; David, D. B. Características fenológicas, produtivas e qualitativas de híbridos de girassol em diferentes épocas de semeadura para produção de silagem. Revista Brasileira de Zootecnia, v.35, p.672-682, 2006.

Mello, R.; Nornberg, J. L.; Rocha, M. G. Potencial produtivo e qualitativo de híbridos de milho, sorgo e girassol para ensilagem. Revista Brasileira de Agrociência, v.10, p. 87-95, 2004.

Porto, W. S.; Carvalho, C. G. P.; Pinto, R. J. B. Adaptabilidade e estabilidade como critérios para seleção de genótipos de girassol. Pesquisa Agropecuária Brasileira, v.42, p.491-499, 2007.

Rezende, A. V.; Evangelista, A. R.; Valeriano, A. R.; Siqueira, G. R.; Rezende, G.; Vilela, H. R.; Lopes, J. Valor nutritivo de silagens de seis cultivares de girassol em diferentes idades de corte. Ciência e Agrotecnologia, v.31, p.896-902, 2007.

Santos, A. C.; Andrade, A. P.; Lima, J. R. S.; Silva, I. F.; Cavalcante, V. R. Variabilidade temporal da precipitação pluvial: nível de nitrogênio e produtividade de cultivares de girassol. Ciência Rural, v.32, p.757-764, 2002.

Sentelhas, P. C.; Ungaro, M. R. G. Índices bioclimáticos para a cultura de girassol. Scientia Agrícola, v.55, p.73-78, 1998.

Silva, M. L. O.; Faria, M. A.; Morais, A. R.; Andrade, G. P.; Lima, E. M. C. Crescimento e produtividade do girassol cultivado na entrassafra com diferentes lâminas de água. Revista Brasileira de Engenharia Agrícola e Ambiental, v.11, p.482488, 2007.

Smiderle, O. J.; Mourão Júnior, M.; Gianluppi, D. Avaliação de cultivares de girassol em savana de Roraima. Acta Amazônica, v.35, p.331-336, 2005.

Tomich, T. R.; Rodrigues, J. A. S.; Gonçalves, L. C.; Tomich, R. G. P.; Carvalho, A. U. Potencial forrageiro de cultivares de girassol produzidos na safrinha para ensilagem. Arquivo Brasileiro de Medicina Veterinária e Zootecnia, v.55, p.756$762,2003$.

Toureiro, C. M.; Serralheiro, R. P; Oliveira, M. R. Resposta das culturas do girassol e do milho a diferentes cenários de rega deficitária. Revista de Ciências Agrárias, v.30, p.33-47, 2007.

Tyagi, N. K.; Sharma, D. K.; Luthra, S. K. Determination of evapotranspiration and crop coeficients of rice and sunflower with lysimeter. Agricultural Water Management, v.45, p.41-54, 2000.

Ungaro, M. R. G. Instruções para a cultura do girassol. Campinas: Instituto Agronômico, 1986. 26p. Boletim Técnico, n.105 